\title{
Large Eddy Simulation of Free Motion of Marine Riser using OpenFOAM
}

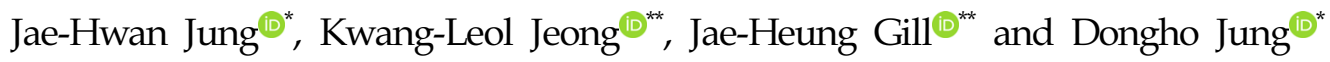 \\ "Korea Research Institude of Ship \& Ocean Engineering Co. Ltd., Daejeong, Korea \\ ${ }^{* *}$ NEXTfoam Co. Ltd., Research Center, Seoul, Korea \\ 오픈폼을 활용한 자유진동하는 라이저 주위 유동의 LES 해석

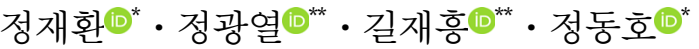 \\ "선박해양플랜트연구소 해양플랜트에너지연구본부 \\ **(주)넥스트폼 기술연구소
}

KEY WORDS: Riser motion 라이저 운동, Large eddy simulation LES, Detached eddy simulation DES, OpenFOAM 오픈폼, Vortex induced vibration 와유기 진동, Lock-in, Reduced velocity 감쇠속도, Rhie-Chow interpolation

\begin{abstract}
In this study, the free motion of a riser due to vortex shedding was numerically simulated with Large Eddy Simulation (LES) and Detached Eddy Simulation (DES) turbulence models. A numerical simulation program was developed by applying the Rhie-Chow interpolation method to the pressure correction of the OpenFOAM standard solver pimpleDyMFoam. To verify the developed program, the vortex shedding around the fixed riser at $R e=3900$ was calculated, and the results were compared with the existing experimental and numerical data. Moreover, the vortex-induced vibration of a riser supported by a linear spring was numerically simulated while varying the spring constant. The results are compared with published direct numerical simulation (DNS) results. The present calculation results show that the numerical method is appropriate for simulating the vortex-induced motion of a riser, including lock-in phenomena.
\end{abstract}

\section{1. 서 론}

해양의 라이저는 와 유기에 의한 진동으로 구조적인 문제가 발생하기도 한다. 그러나 라이저는 매우 길고 가늘기 때문에 실 험과 수치해석이 매우 어려운 문제가 있다. 길이가 매우 긴 라 이저를 직접 수치적으로 해석하는 것은 현실적으로 불가능하기 때문에 대부분 짧은 영역만을 해석대상으로 연구를 진행하였다 (Lysenko et al., 2012; Chen and Mercier, 2006). 라이저는 일반적 으로 레이놀즈수 $10^{5} \sim 10^{7}$ 영역에서 운용되는데 높은 레이놀즈수 에서 와흘림을 정교하게 해석하기 위하여 많은 연구들은 Large eddy simulation(LES)을 이용하여 수치해석을 수행하였다(Jung et al., 2012; Chen and Mercier, 2006; Chen et al., 2018; Lysenko et al., 2012). Reynolds averaged Navier-Stokes(RANS)모델은 와 흘 림에 의한 진동의 진폭을 과도하게 크게 해석하는 경향이 있어
적합하지 않은 것으로 알려져 있다(Catalano et al., 2003). 라이 저의 짧은 부분만을 해석하는 것은 한계가 있으므로 Bao et al.(2016)은 높이 별로 몇 개의 얇은 영역을 동시에 해석하는 수 치적 방법을 제안하였다. 각 높이별 영역의 라이저들은 연동하 여 움직이게 되는데 라이저의 구조적 변형은 Linearized tensioned beam으로 가정하여 단순하게 해석하였다.

본 연구의 최종적인 목표는 높이에 따라 독립된 유동장을 해 석하여 라이저 전체의 거동을 해석할 수 있는 수치해석 프로그 램을 개발하는 것이고 본 논문에서는 그 중간단계로서 자유동 요하는 라이저의 운동과 주위 유동을 해석하기 위한 수치적 기 법을 개발하고 검증하는 것이다. 본 논문에서는 OpenFOAM을 이용하여 개발한 유동해석 프로그램의 수치적 방법을 설명하고 고정된 라이저와 Surge, Sway 운동이 자유로운 라이저의 와 흘 림 현상을 해석하여 기존의 연구 결과와 비교하였다.

Received 16 August 2019, revised 4 October 2019, accepted 16 October 2019

Corresponding author Kwang-Leol Jeong: +82-70-8796-3022, kl.jeong@nextfoam.co.kr ORCID: https://orcid.org/0000-0002-2109-9287 It is noted that this paper is revised edition based on proceedings of KAOST 2019 in Jeju. 


\section{2. 수치기법}

\section{1 속도와 압력의 연성}

본 논문의 연구대상인 라이저 주변의 와유기 현상은 비압축 성, 비정상, 단상유동 이므로 OpenFOAM의 표준솔버인 pimple DyMFoam으로 해석이 가능하다. OpenFOAM의 표준솔버는 질 이 좋은 격자에서는 만족스러운 결과를 주지만 격자의 질에 따 라 해석결과의 영향이 큰 단점을 갖고 있다. 이러한 문제를 해 결하기 위해서 표준솔버의 압력 교정방법에 Rhie-Chow 보간법 을 적용하였다. 지배방정식인 Navier-Stokes 방정식의 시간항을 Euler implicity로 이산화 하게 되면 식 (1)과 같다. 식 (1)의 $S$ 는 면적, $\rho$ 는 밀도, $\Gamma$ 는 확산계수, $p$ 는 압력, $U$ 는 속도를 의미한다. 아래첨자 $f_{f}$ 는 격자면에서의 값, $p$ 는 격자중심에서의 물리량을 의미하고, 위첨자 ${ }^{n}$ 은 현재의 시간단계, ${ }^{0}$ 는 이전시간단계를 의 미한다.

$$
\begin{aligned}
& \frac{\rho U_{p}^{n}-\rho U_{p}^{0}}{d t}+\sum_{f} S_{f} \cdot\left(\rho U^{0} U^{n}\right)_{f} \\
& -\sum_{f} S_{f} \rho \Gamma U^{n} \cdot\left(\nabla U^{n}\right)_{f}=-\frac{1}{\rho} \nabla\left(p^{n}\right)_{p}
\end{aligned}
$$

현재 시간단계의 속도 $U_{p}^{n}$ 을 계산하기 위하여 이전 시간단계 의 압력과 속도를 이용하여 중간시간단계 $U_{p}^{*}$ 표현하면 식 (2) 와 같이 표현할 수 있다. 위 첨자 ${ }^{*}$ 은 중간 시간단계를 의미한 다. $a_{p}$ 는 $U_{p}^{*}$ 의 계수, $H$ 는 $U_{0}$ 를 독립변수로 갖는 함수, $V_{p}$ 는 격자 의 체적을 의미한다.

$$
a_{p} U_{p}^{*}=H\left(U^{0}\right)-V_{p}\left(\nabla p^{0}\right)_{p}
$$

임시속도 $U_{p}^{*}$ 에서 압력구배에 의한 효과를 제거하고 격자면 의 임시 flux $F^{*}$ 를 계산하면 식 (3)과 같다. 격자면의 임시 flux 를 계산하는 Rhie-Chow 보간법에 대한 자세한 설명은 Rhie and Chow(1983)에서 찾아볼 수 있다.

$$
F^{*}=\left[U_{p}^{*}+\frac{V_{p}}{a_{p}}(\nabla p)_{p}\right]_{f} \cdot S_{f}
$$

연속방정식을 만족시키기 위해서는 격자의 발산이 ' 0 '이 되어 야 하므로 발산이 ' 0 '이 되는 압력을 포아송방정식 식 (4)를 이 용하여 계산하였다.

$$
\nabla \cdot\left(\frac{V_{p}}{a_{p}}\left(\nabla p^{*}\right)_{p}\right)=\sum_{f} F^{*}
$$

계산된 압력을 이용하여 격자면의 Flux와 격자점의 속도를 식 (5)와 같이 보정할 수 있다. 보정된 격자면의 Flux와 속도를 이 용하여 식 (3)-(5)의 과정을 1회 더 반복하여 현제 시간단계의 속도와 압력을 계산하였다. 지배방정식의 대류항은 제한자 (Limiter)가 있는 2차 중심차분법으로 이산화 하였으며 확산항과
난류방정식의 이산화에는 2 차 중심차분법을 이용하였다.

$$
\begin{aligned}
F^{* *} & =F^{*}-\frac{V_{p}}{a_{p}}\left|S_{f}\right| \vec{n} \cdot\left(\nabla p^{*}\right)_{f} \\
U_{p}^{* *} & =U_{p}^{*}-\frac{V_{p}}{a_{p}}\left(\nabla p^{*}-\nabla p\right)_{p}
\end{aligned}
$$

개발된 프로그램을 검토하기 위하여 Fig. 1과 같이 이웃한 격 자간의 크기차이가 큰 격자를 이용하여 원형실린더 주위 유동 을 계산하였다. OpenFOAM에 포함된 프로그램(표준 솔버)과 개 발된 프로그램으로 해석한 압력분포를 Fig. 2에 나타냈다. 표준 솔버의 경우 격자 간 크기 차이가 커지는 영역에서 압력이 불 연속으로 나타나는 데 반하여 본 연구에서 개발된 프로그램의 경우 매끄럽게 나타나는 것을 볼 수 있다.
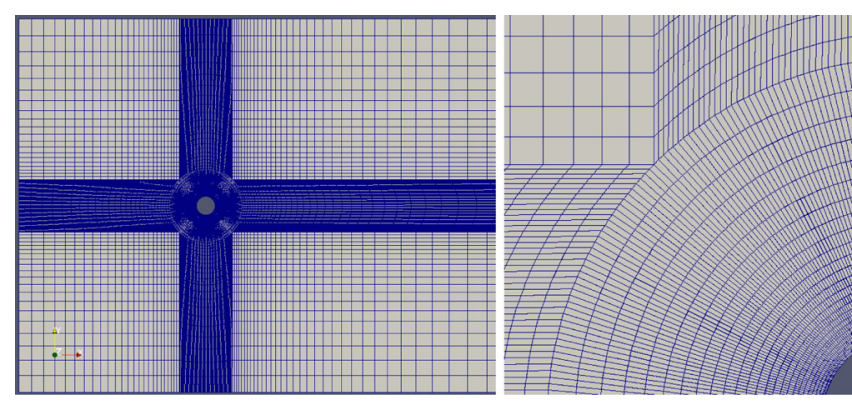

Fig. 1 2-D grid system for solver comparison

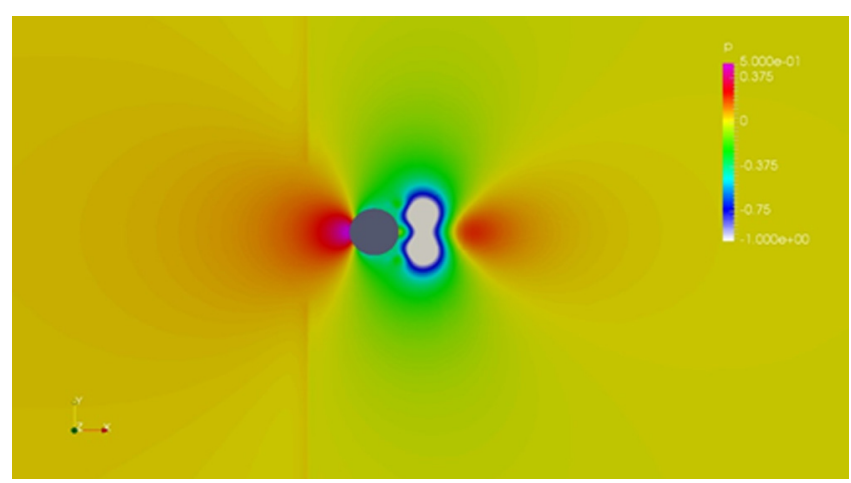

(a) standard solver

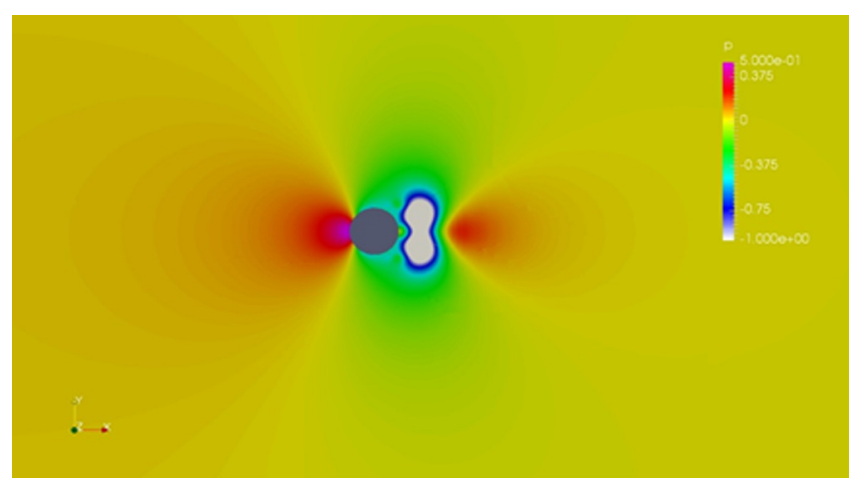

(b) developed solver

Fig. 2 Comparison of pressure and velocity fields of standard and developed solvers 


\section{2 난류모델}

계산에 사용된 난류모델은 LES계열의 Dynamic $k$ equation 모 델(Kim and Menon, 1995)과 LES와 RANS가 혼합된 $k$-Omega Shear stress transport(SST) Detached eddy simulation(DES) 모델 (Menter et al., 2003)이다. Dynamic $k$ equation모델은 와점도 계 산에 Smagoringsky 상수 대신 난류에너지 수송방정식으로 계산 된 난류에너지를 사용하여 와점도를 계산하는 것이 가장 큰 특 징이다. 난류에너지의 생성과 소산의 평형이 자연스럽게 만족 되고 Non-local 효과와 History 효과가 해석에 고려되는 장점을 갖고 있다. $k$-Omega SST DES(Detached eddy simulation)모델은 난류 Length scale이 Filter width보다 크면 RANS모델인 $k$-Omega SST 모델로 해석하고 Filter width보다 작으면 LES로 해석하는 난류모델이다. 난류모델은 OpenFOAM의 표준라이브러리를 이 용하였다.

\section{3 라이저 거동을 위한 동적격자}

라이저가 자유운동을 하는 조건을 해석하기 위해서 라이저의 거동에 따라 격자가 변형되는 OpenFOAM의 동적격자를 적용하 였다. 라이저에 가까운 격자점 $\left(d<d_{n e a r}\right)$ 은 라이저와 동일하게 이동하고 라이저와 멀리 떨어진 격자점 $\left(d>d_{f a r}\right)$ 은 고정되어 이 동하지 않도록 하였다. 중간의 격자점은 거리에 따라 식 (6)과 같이 보간하여 이동량을 결정하였다. 식 (6)의 $R$ 은 변위벡터를 의미한다. 격자점의 이동속도는 식 (7)과 같이 계산되고 식 (8) 과 같이 격자점의 이동속도를 지배방정식과 수송방정식의 대류 항의 속도에서 빼주어 격자의 이동을 고려할 수 있다.

$$
\begin{aligned}
& R=R_{\text {riser }} \cdot \frac{\cos \left(\frac{d-d_{\text {near }}}{d_{\text {far }}-d_{\text {near }}} \pi\right)+1}{2} \\
& U_{\text {mesh }}=\left(R^{n}-R^{n-1}\right) / d t \\
& \frac{d}{d t} \int_{V} \phi d V+\int_{S}\left(U-U_{\text {mesh }}\right) \phi d S=\int_{S} q_{\phi} d S+\int_{V} s(\phi) d V
\end{aligned}
$$

\section{3. 고정된 라이저의 와유기}

실험과 수치해석 결과가 많이 공개되어있는 $R e=3900$ 에서 원형 라이저의 와유기 현상을 해석하였다. Fig. 3은 해석영역과 격자계를 보여준다. 해석영역의 높이는 와유기의 3 차원적 현상 이 나타날 수 있도록 설정해야 한다. 많은 연구들이 실린더 직 경의 원주율 $(\pi)$ 배를 해석영역의 높이로 설정하였으며(Lysenko et al., 2012), 본 연구에서도 직경의 $\pi$ 배로 설정하였다. 격자는 OpenFOAM의 SnappyHexMesh를 이용하여 작성하였다. LES모델 은 일반적으로 벽함수를 쓰지 않으므로 라이저의 첫 번째 경계 층 격자의 크기는 $y^{+}$가 1 이 되도록 설정하였다. 이 경우 첫 번 째 경계층 격자의 높이는 라이저 직경의 약 $0.4 \%$ 이다. $k$-Omega $\mathrm{SST} \mathrm{DES}$ 의 경우 벽함수를 사용할 수 있지만 본 연구에서는 동 일한 격자를 이용하기 위하여 벽함수를 쓰지 않았다. 높이방향 격자의 수는 96 개, 원주방향으로는 184 개 이다. 전체 경계층 격 자는 10 개이고 전체 격자수는 $3,270,060$ 개이다. 시간간격은 라
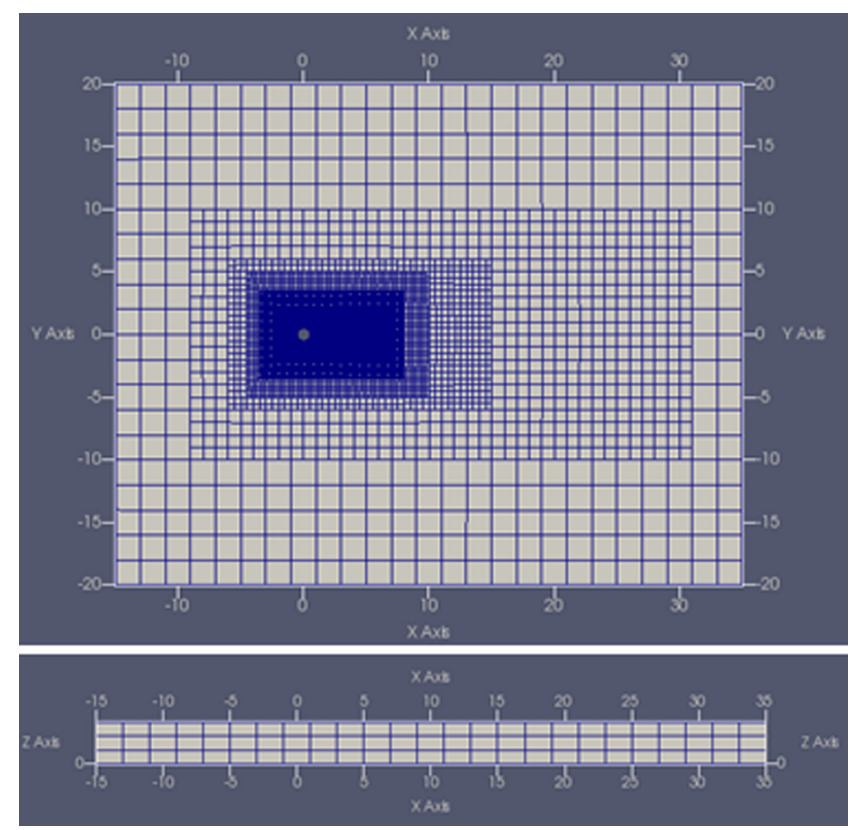

(a) Calculation domain
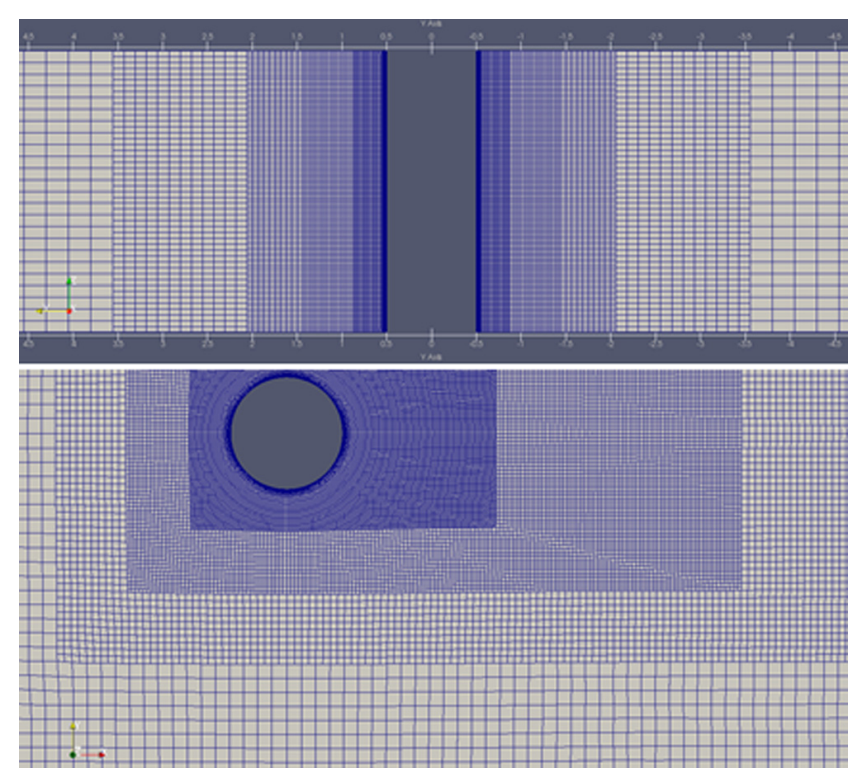

(b) grid shape around the circular riser

Fig. 3 Calculation domain and grid system for fixed circular riser at $R e=3900$

이저 직경을 유입속도로 나누어 얻은 시간의 0.0025 배로 설정하 였다. 이 경우 최대 Courant 수는 약 0.4 정도로 낮게 유지할 수 있다. 라이저의 상부와 하부는 모든 물리량이 같도록 순환 (Cyclic)경계조건을 주어 주기적인 유동 특성이 나타나도록 하 였다.

Fig. 4는 라이저 표면의 압력계수의 시간평균 값을 공개된 실 험/수치해석 결과와 비교한 그림이다. 본 연구에서 계산된 표면 압력 분포가 기존의 실험/수치해석에 근접한 결과를 보이고 있 음을 볼 수 있다. Fig. 5는 라이저 뒤쪽 후류의 속도분포를 비교 한 그림이다. 후류의 속도분포는 실험에 따라 다소 차이가 있지 만 본 연구의 수치해석 결과가 비교적 최근인 Parnaudeau et al. 


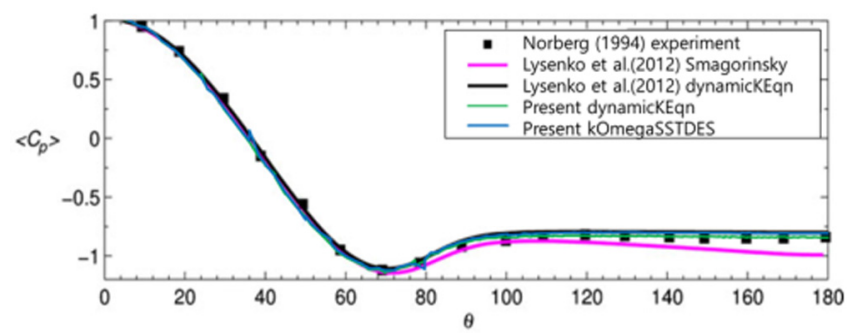

Fig. 4 Time averaged pressure coefficient distribution on the riser surface at $R e=3900$

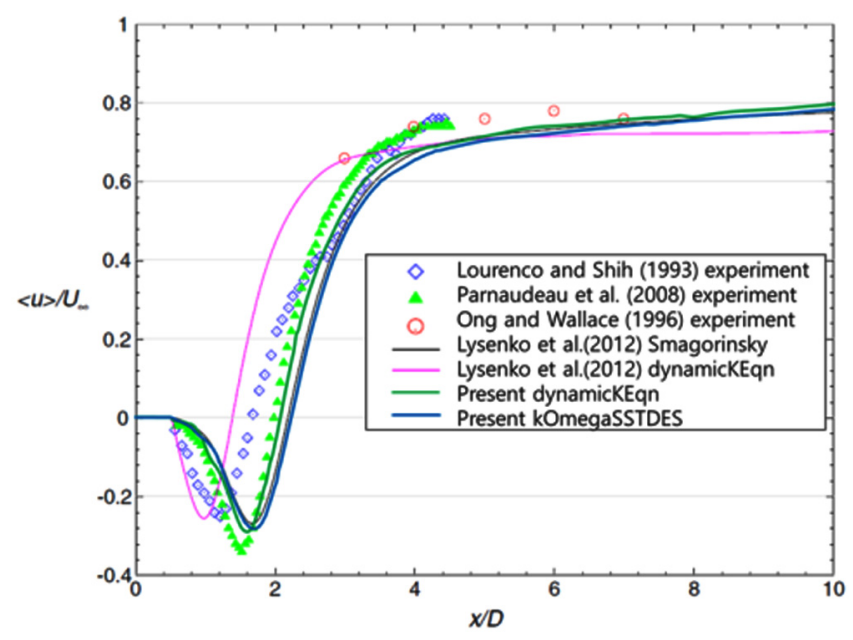

Fig. 5 Time averaged X-directional velocity distribution on the center plane at $R e=3900$

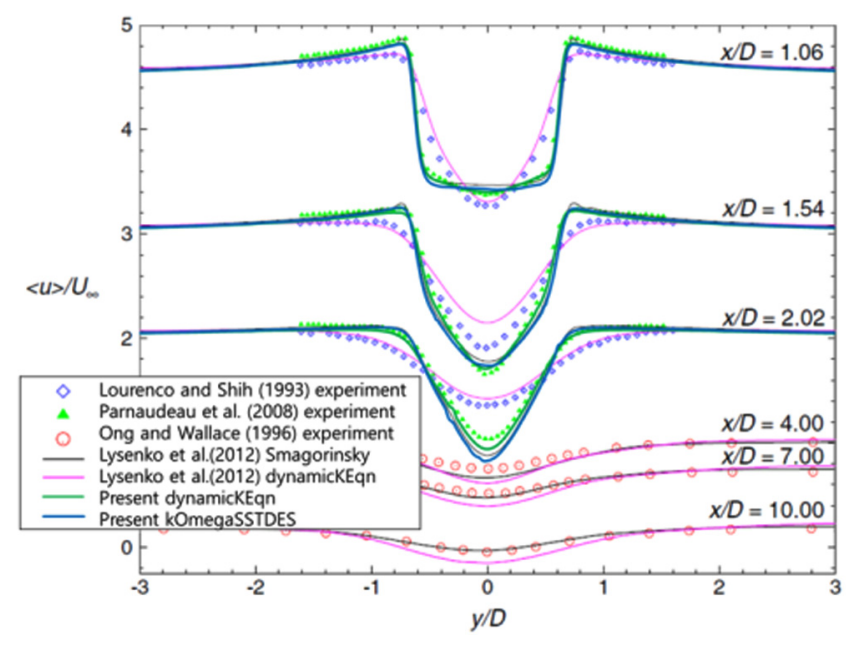

Fig. 6 Time averaged X-directional velocity distribution on each cross section at $R e=3900$

(2008)의 실험에 근접하는 것을 볼 수 있다. 압력분포와 속도분 포를 통하여 Dynamic $k$ equation 모델과 $k$-Omega SST DES모델 간의 우열은 뚜렷하게 나타나지 않는다. Lysenko et al.(2012)의 수치해석에서 Dynamic $k$ equation 모델은 본 연구와 유사한 경 향을 보이고 있으나 Smagorinsky 모델을 사용하는 경우 다소 차 이가 있는 것을 볼 수 있다.

Fig. 6과 Fig. 7은 후류의 X-방향 속도와 Y-방향 속도의 분포

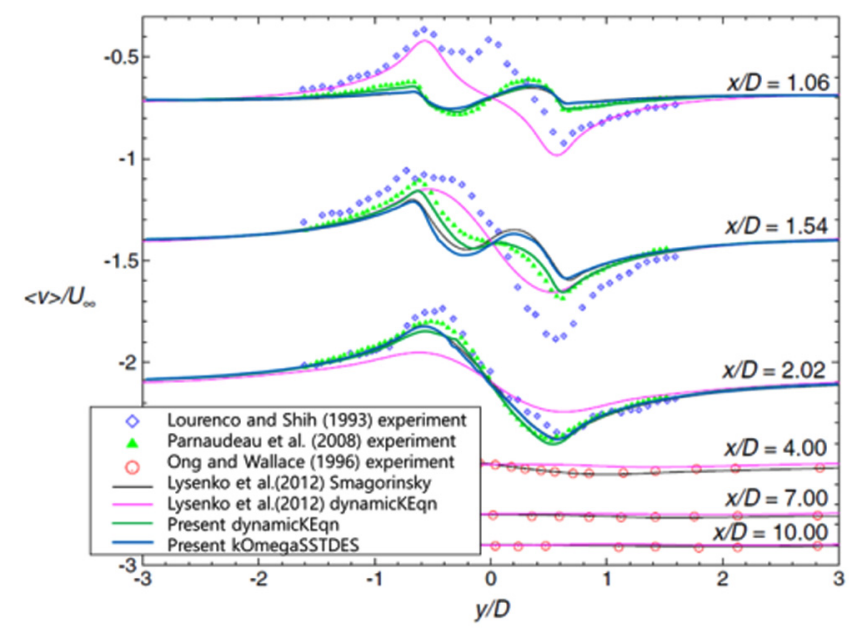

Fig. 7 Time averaged Y-directional velocity distribution on each cross section at $R e=3900$

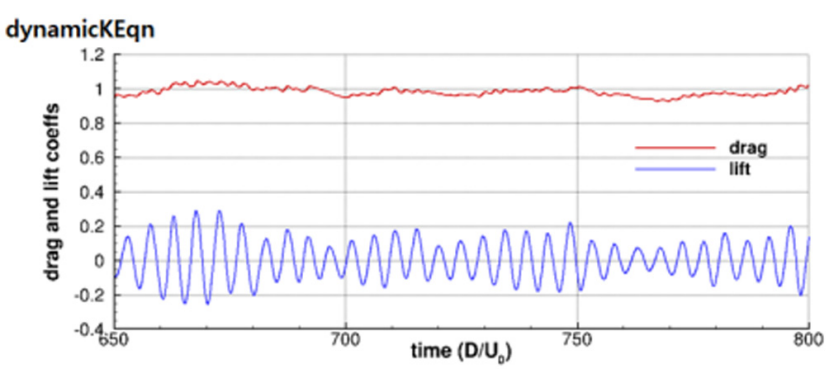

\section{kOmegaSSTDES}

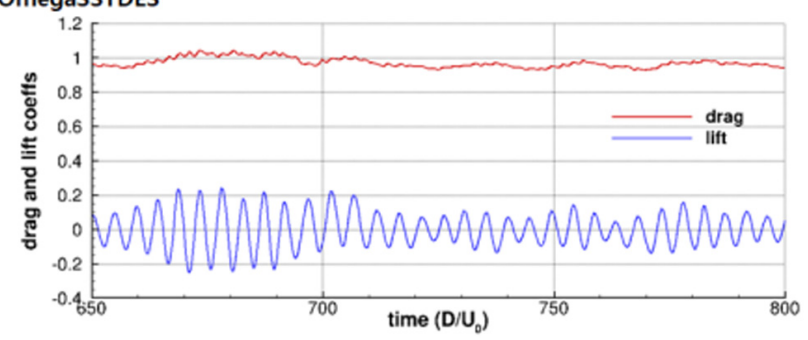

Fig. 8 Time histories of drag and lift coefficient

를 비교한 그림이다. 라이저로부터 직경의 3 배 이상 떨어진 경 우 격자의 크기가 커서 비교가 적절하지 않다고 생각하여 2.02 배 까지만 비교하였다. 전체적으로 Parnaudeau et al.(2008)의 실 험과 잘 일치하는 것을 볼 수 있다. Lysenko et al.(2012)의 연구 에서 dynamicKEqn 모델은 Parnaudeau et al.(2008)의 실험에 근 접하고, Smagorinsky 모델은 Lourenco and Shih(1993)의 실험에 근접한 결과를 보이는 것처럼 난류모델에 따라 경향이 많이 다 르게 나타난다.

Fig. 8은 라이저의 양력과 항력 계수의 시계열을 보여준다. 진 폭이 일정하지는 않지만 주기적인 변동이 나타나는 것을 볼 수 있다. 시계열 자료를 이용하여 평균항력과 양력의 제곱평균제 곱근(Root mean square, RMS), 스트로할수(Strouhal number, St)를 계산하여 기존의 연구결과들과 비교하면 Table 1과 같다. 항력 과 양력, 스트로할수 모두 기존의 연구들의 범위에 있는 것을 볼 수 있다. 본 연구에서 개발된 수치기법이 고정된 라이저의 와유기 현상을 잘 모사하는 것으로 여겨진다. 
Table 1 Comparison of drag and lift coefficient and Strouhal number with other research data

\begin{tabular}{|c|c|c|c|c|}
\hline & Method & $\mathrm{Cd}$ & $\begin{array}{c}C l \\
(\mathrm{RMS})\end{array}$ & $S t$ \\
\hline \multirow{2}{*}{ Present cal. } & dynamicKEqn & 0.985 & 0.115 & 0.211 \\
\hline & kOmegaSSTDES & 0.975 & 0.103 & 0.211 \\
\hline \multirow{2}{*}{$\begin{array}{l}\text { Lysenko et al. } \\
\qquad(2012)\end{array}$} & Smagorinsky & 1.18 & 0.44 & 0.19 \\
\hline & dynamicKEqn & 0.97 & 0.09 & 0.209 \\
\hline $\begin{array}{l}\text { Lourenco and } \\
\text { Shih (1993) }\end{array}$ & PIV & 0.99 & - & 0.22 \\
\hline $\begin{array}{l}\text { Ma et al. } \\
(2000)\end{array}$ & DNS & 0.84 & - & 0.22 \\
\hline $\begin{array}{l}\text { Wornom et al. } \\
\text { (2011) }\end{array}$ & LES & 0.99 & 0.11 & 0.21 \\
\hline $\begin{array}{c}\text { Ouvrard et al. } \\
\text { (2010) }\end{array}$ & LES & 0.94 & 0.092 & 0.22 \\
\hline $\begin{array}{l}\text { Meyer et al. } \\
\text { (2010) }\end{array}$ & LES & 1.05 & - & 0.21 \\
\hline $\begin{array}{c}\text { Norberg } \\
(1994,2001)\end{array}$ & Exp. & 0.98 & $0.04 \sim 0.15$ & - \\
\hline
\end{tabular}
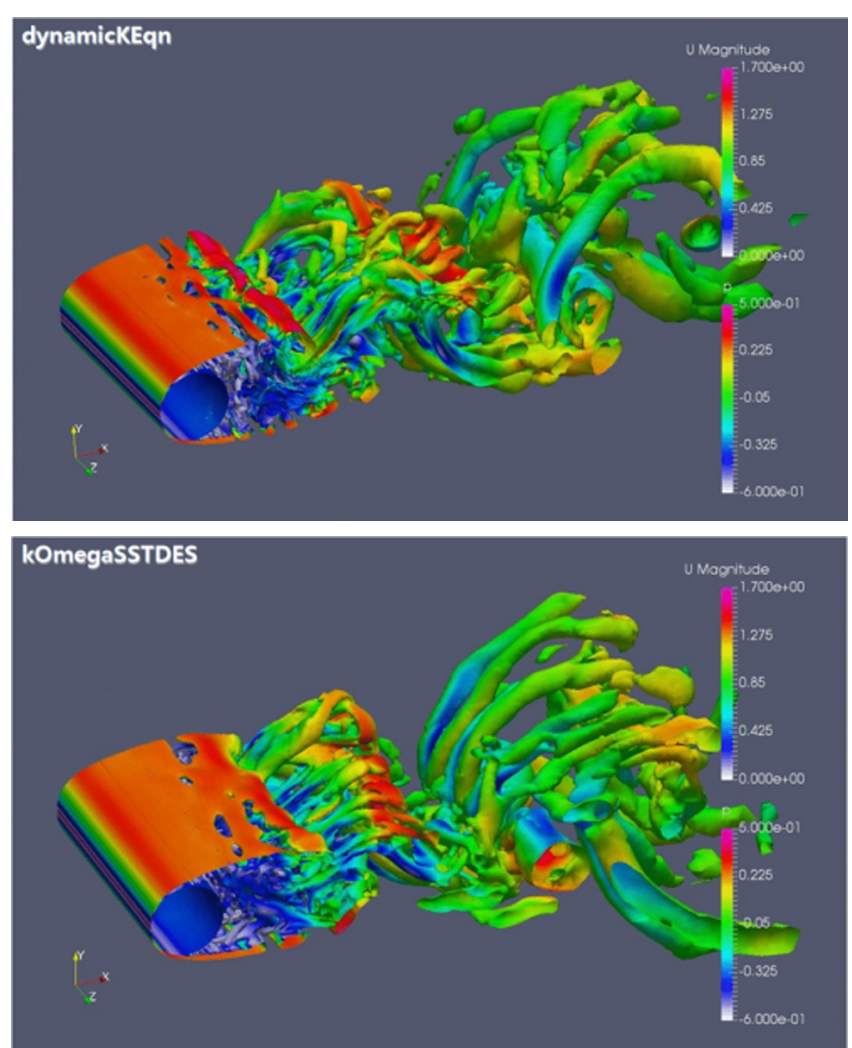

Fig. 9 ISO surface of $Q=0.5$ with velocity magnitude contour

Fig. 9는 $Q=0.5$ 인 면을 가시화한 그림이다. $Q$ 는 와도(Vorticity)와 변형속도(Rate of strain)의 차이를 의미하고 $1 / 2\left\{\operatorname{tr}(D)^{2}-\operatorname{tr}\left(D^{2}\right)\right\}$ 으 로 계산된다. $D$ 는 속도구배 텐서 $\partial u_{i} / \partial x_{j}$ 을 의미한다. 두 난류모델 모두 주기적인 와흘림 현상이 명확하게 나타나고 있으며, Shear layer에서 유기된 작은 와가 병합되면서 유동에 수직한 방향으로
회전하는 주 와류(Primary vortex)와 유동 방향으로 회전하면서 길이 가 늘어나는 갈비뼈 모양의 와(Rib-shape streamwise vortex)로 발전 되는 현상이 잘 나타나고 있다. 유기된 와의 주기성과 갈비뼈 모양 의 와가 길게 늘어나는 현상은 $k$-Omega SST DES 모델에서 더 뚜렷하게 나타나고 있으며, Shear layer vortex의 흘림현상은 Dynamic $k$ equation모델에서 더 뚜렷하게 나타난다.

\section{2-자유도 라이저의 Lock-in}

고정된 라이저의 해석과 동일한 조건에서 라이저에 병진운동 자유도를 주어 라이저의 자유진동을 해석하였다. 해석에 사용 된 난류모델은 Dynamic $k$ equation 모델이다. 식 (9)는 운동방정 식으로 이를 무차원화 하면 식 (10)과 같다. 식 (9)의 $Y$ 는 변위 량을 의미하고, $m$ 은 질량, $c$ 는 감쇠계수, $k$ 는 스프링상수이고 식 (10)의 $l$ 은 라이저의 길이를 의미한다. 라이저 거동에서 감쇠 계수 $C$ 는 ' 0 '이므로 질량비 $n$ 과 스프링의 강도를 나타내는 감 쇠속도 $U^{*}$ 가 라이저의 거동에 주요한 인자가 된다. 본 연구에 서는 Table 2 와 같이 실린더와 같은 체적의 유체질량과 실린더 질량의 비(질량비)가 2 이고 감쇠속도가 3 과 6,9 인 조건에서 해 석을 수행하였다.

$$
\begin{aligned}
& m \ddot{Y}+c \dot{Y}+k Y=F(t) \\
& \ddot{y}+\dot{C} y+K y=\frac{1}{2 n} C_{L} \\
& y=\frac{Y}{D}, \quad C=2 \xi\left(\frac{2 \pi}{U^{*}}\right), K=\left(\frac{2 \pi}{U^{*}}\right)^{2}, n=\frac{m}{\rho \pi(0.5 D)^{2} l} \\
& \xi=\frac{c}{2 \sqrt{k m}}, \quad U^{*}=\frac{U}{f_{n} D}, f_{n}=\frac{1}{2 \pi} \sqrt{\frac{k}{m}}
\end{aligned}
$$

라이저의 변위 시계열을 Gsell et al.(2016)의 Direct numerical simulation(DNS) 결과와 비교하여 Fig. 10 에 나타냈다. $U^{*}$ 가 3 인 조건에서는 정량적/정성적으로 기존의 연구결과와 매우 유사한 결과를 보이는 것을 볼 수 있다. 진폭이 가장 큰 $U^{*}$ 가 6 인 조건 에서는 주기가 다소 짧게 나타나지만 전체적으로 유사한 경향 을 보이고 있다. $U^{*}$ 가 9 인 조건에서는 장주기의 변동이 지속적 으로 발생하기 때문에 푸리에 변환으로 장주기 성분을 제거하 여 내타냈다. 라이저의 진폭과 주기가 Gsell et al.(2016)의 DNS 해석 결과와 매우 유사함을 볼 수 있다. Fig. 10의 시계열 데이 터로 라이저의 궤적을 나타내면 Fig. 11과 같다. Fig. 11은 궤적 의 특성을 더 뚜렷하게 표현하기 위하여 가로세로비를 임의로 표현하였다. $U^{*}$ 가 3 인 경우 숫자 8 에 가까운 형태로 운동하게 되고 $U^{*}$ 가 9 인 경우에는 Surge운동이 매우 작아 sway 운동이 주로 나타나게 된다. Gsell et al.(2016)의 DNS 결과와 매우 유사

Table 2 Computational conditions for lock-in simulation of riser

\begin{tabular}{cccc}
\hline \hline$U^{*}$ & 3 & 6 & 9 \\
$K$ & 21.635 & 5.409 & 2.404 \\
$n$ & & 2 & \\
\hline
\end{tabular}




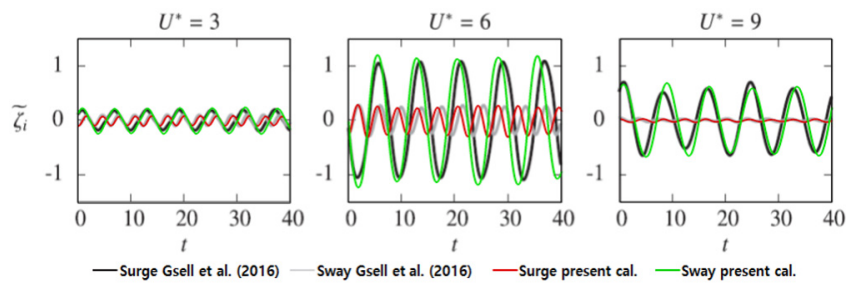

Fig. 10 Comparison of time history of riser displacement with Gsell et al. (2016)
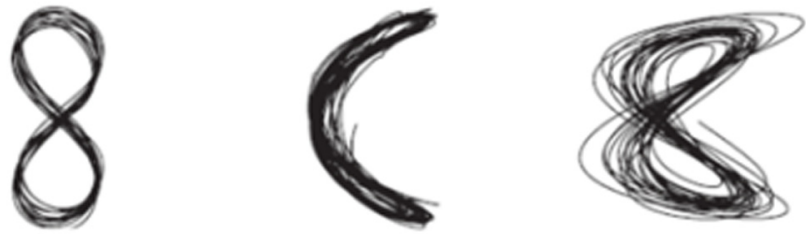

Gsell et al. (2016)
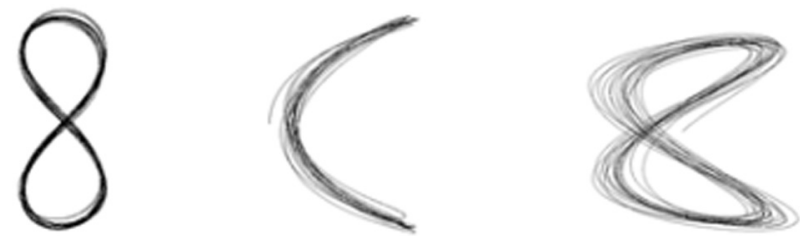

Present cal.

Fig. 11 Comparison of trajectory of riser with Gsell et al. (2016) (not at scale)

Table 3 Drag and lift coefficient and Strouhal number in each condition

\begin{tabular}{cccc}
\hline \hline$U^{*}$ & 3 & 6 & 9 \\
$C d$ & 1.720 & 3.075 & 1.2273 \\
$C l(\mathrm{RSM})$ & 2.697 & 1.771 & 0.021 \\
$\mathrm{St}$ & 1.03 & 0.83 & 0.76 \\
\hline
\end{tabular}

한 경향을 보이는 것을 볼 수 있다. 본 연구의 해석 방법이 라 이저 거동에 적합한 것으로 생각된다.

Table 3은 각 감소속도에서 향력과 양력, 스트로할 수를 보여 준다. $U^{*}$ 가 6 인 조건에서 항력이 가장 크게 나타나고 $U^{*}$ 가 3 인 조건에서 양력이 가장 크게 나타난다.

Fig. 12는 진동하는 라이저 주위 와류의 한 주기 동안의 형상 을 $Q=0.5 \mathrm{ISO}$ 면으로 표현한 그림이다. 고정된 라이저에 비하 여 와가 더 넓게 분포하게 되고 와의 주기성이 더 뚜렷하게 나 타난다. 라이저의 변위가 최대가 되는 지점에서 와 흘림이 발생 하기 때문에 유동방향에 수직한 주 와류의 간격이 폭 방향으로 넓게 나타나고 서로 회전방향이 반대인 주 와를 연결하는 갈비 뼈 모양의 와가 더 길게 나타나는 특징이 있다. Sway 운동의 진 폭이 가장 작은 $U^{*}$ 가 3 인 조건에서는 와의 구조가 가장 단순한 형태를 보이고 진폭이 큰 $U^{*}$ 가 6 인 조건에서 구조가 가장 복잡 하게 나타난다. Surge 운동의 진폭이 작은 $U^{*}$ 가 9 인 조건에서 는 가장 늦게 3 차원적 와류 특성이 나타나는 것을 볼 수 있다. $U^{*}$ 가 3 인 조건에서 Cross-flow 방향의 진폭이 더 크게 나타남에

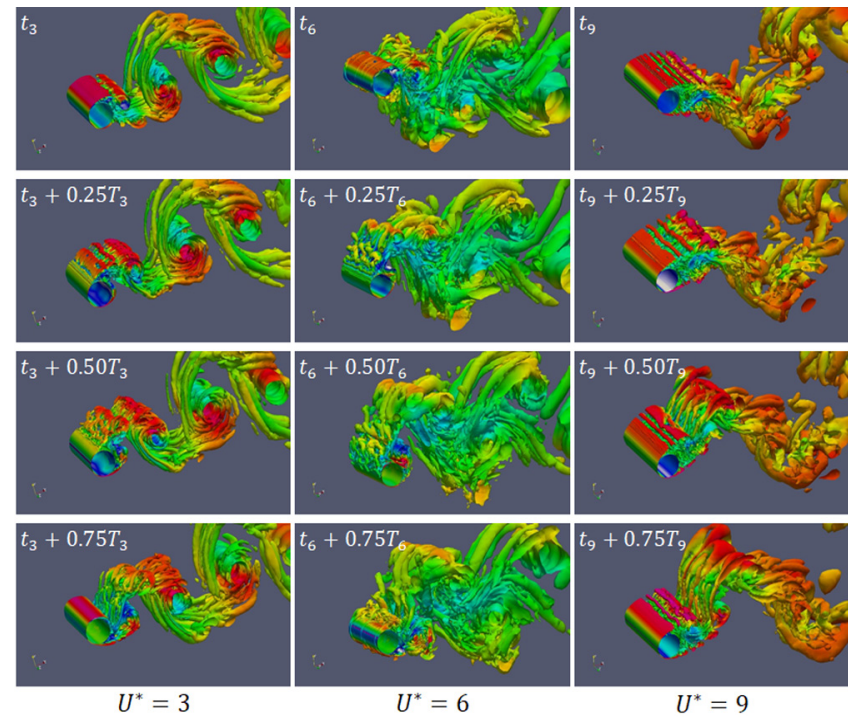

Fig. 12 ISO surface of $Q=0.5$ with velocity magnitude contour for 2-DoF riser

도 $U^{*}$ 가 9 인 조건에서 3 차원적 특성이 늦게 나타나는 것으로 보아 In-line 방향의 운동이 와류의 3 차원적 특성에 큰 영향을 미치는 것으로 생각된다.

\section{5. 결 론}

본 논문에서는 라이저의 와유기진동과 그로인한 라이저의 거 동을 해석하기 위한 유동해석 프로그램을 소스코드가 공개된 전산유체역학(Computational fluid dynamics, CFD) 라이브러리인 OpenFOAM을 이용하여 개발하였다. 수치해석 프로그램의 정도 를 향상시키기 위하여 압력교정 방법에 Rhi-Chow interpolation 을 적용하여 해석 정도가 향상된 것을 확인하였다.

$R e=3900$ 에서 고정된 원형 라이저의 와유기 현상을 Dynamic $k$ equation 모델과 $k$-Omega SST DES 모델로 해석하여 기존의 연구 결과와 비교하여 검증하였다. 정량적/정성적으로 기존의 연구 결과들과 잘 일치하고 정성적 특성들을 잘 보여주는 것으 로 판단된다. Dynamic $k$ equation 모델과 $k$-Omega SST DES 모 델 모두 정량적으로 근사한 결과를 보여주고 있어 두 모델 모 두 라이저의 와유기 해석에 적합한 것으로 생각된다.

와유기에 의한 2 자유도 라이저의 진동을 해석하고 기존의 $\mathrm{DNS}$ 해석결과와 비교하여 검증하였다. 진폭이 매우 큰 경우 $\mathrm{DNS}$ 해석 결과에 비하여 주기가 약간 짧아지는 결과가 나오지 만 전체적으로 진폭과 주기가 기존의 DNS 결과와 유사한 것을 확인하였다. 라이저 이동에 의하여 격자점이 이동하여도 와의 생성과 발달과정이 미끄럽게 해석되어 본 연구에서 적용된 OpenFOAM의 동적격자 알고리즘이 자유동요하는 라이저 해석 에 적합한 것으로 판단된다.

본 연구에서는 라이저의 짧은 영역만을 해석 대상으로 하였 다. 향후, 본 연구의 결과를 발전시켜 높이별로 다수의 유체영 역을 동시에 해석하고 각 유체영역의 해석결과를 구조해석과 연동하기 위한 수치적 방법을 연구할 것이다. 


\section{후기}

본 논문은 선박해양플랜트연구소의 주요사업인 '초심해역용 라이저(SLWR) 설계엔지니어링 핵심기술 개발’에 의해 수행 되 었습니다(PES3060).

\section{References}

Bao, Y., Palacios, R., Graham, M., Sherwin, S., 2016. Generalized Thick Strip Modelling for Vortex-induced Vibration of Long Flexible Cylinders. Journal of Computational Physics, 321, 1079-1097. https://doi.org/10.1016/j.jcp.2016.05.062

Catalano, P., Wang, M., Iaccarino, G., Moin, P., 2003. Numerical Simulation of the Flow around a Circular Cylinder at High Reynolds Numbers. International Journal of Heat and Fluid Flow, 24(4), 463-469. https://doi.org/10.1016/S0142-727X(03) 00061-4

Chen, H.C. Liu, X. Liu, F., Lou, M., 2018. Optimal Desing of Two-dimensional Riser Fairings for Vortex-induced Vibration Suppression Based on Genetic Algorithm. arXiv:1801.03792, Cornell University.

Chen, H.C., Chen, C.R., Mercier, R.S., 2006. CFD Simulation of Riser VIV. OTRC Project Final Report, MMS Project Number 481.

Gsell, S., Bourguet, R., Braza, M., 2016. Two-degree-of-freedom Vortex-induced Vibration of a Circular Cylinder at $\mathrm{Re}=3900$. Journal of Fluids and Structures, 67, 156-172. https://doi.org/ 10.1016/j.jfluidstructs.2016.09.004

Jung, J.H., Yoon, H.S., Choi, C.Y., Chun, H.H., Park, D.W., 2012. Large Eddy Simulation of Flow around Twisted Offshore Structure with Drag Reduction and Vortex Suppression. Journal of the Society of Naval Architecture of Korea, 49(5), 440-446. https://doi.org/10.3744/SNAK.2012.49.5.440

Kim, W.W., Menon, S., 1995. A New Dynamic One-Equation Subgrid-scale Model for Large Eddy Simulations. $33^{\text {rd }}$ Aerospaces Sciences Meeting and Exhibit, Reno USA, 356. https://doi.org/10.2514/6.1995-356

Lourenco, L.M., Shih, C., 1993. Characteristics of the Plane Turbulent Near Wake of a Circular Cylinder; A Particle Image Velocity Study. Technical Report TF-62, CTR Annual Research Briefs, NASA Ames/Stanford University.
Lysenko, D.A., Ertesvag, I.S., Rian, K.E., 2012. Large-Eddy Simulation of the Flow over a Circular Cylinder at Reynolds Number 3900 Using the OpenFOAM Toolbox. Flow Turbulence Combust, 89(4), 491-518. https://doi.org/10.1007/s10494-0129405-0

Ma, X., Karamanos, G.S., Karniadakis, G.E., 2000. Dynamics and Low-dimensionality of a Turbulent Near Wake. Journal of Fluid Mechanics, 410, 29-65. https://doi.org/10.1017/S0022112099 007934

Menter, F.R., Kuntz, M., Langtry, R., 2003. Ten Years of Industrial Experience with the SST Turbulence Model. Turbulence, Heat and Mass Transfer, 4, 625-632.

Meyer, M., Hickel, S., Adams, N.A., 2010. Assessment of Implicit Large-eddy Simulation with a Conservative Immersed Interface Method for Turbulent Cylinder Flow. International Journal of Heat and Fluid Flow, 31(3), 368-337. https://doi.org/10.1016/ j.ijheatfluidflow.2010.02.026

Norberg, C., 1994. An Experimental inverstigation of the Flow around a Circular Cylinder: Influence of Aspect Ration. Journal of Fluid Mechanics, 258, 287-316. https://doi.org/10.1017/S0022 112094003332

Norberg, C., 2001. Flow around a Circular Cylinder: Aspects of Fluctuating Lift. Journal of Fluids and Structures, 15(3-4), 459-469. https://doi.org/10.1006/jfls.2000.0367

Ouvard, H., Koobus, B., Dervieux, A., Salvetti, M.V., 2010. Classical and Variational Multiscale LES of the Flow around a Circular Cylinder on Unstructured Grids. Computers \& Fluids, 39(7), 1083-1094. https://doi.org/10.1016/j.compfluid.2010.01.017

Parnaudeau, P., Carlier, J., Heitz, D., Lamballais, E., 2008. Experimental and Numerical Studies of the Flow over a Circular Cylinder at Reynolds Number 3900. Physics of Fluids, 20(8), 085101. https://doi.org/10.1063/1.2957018

Rhie, C.M., Chow, W.L., 1983. Numerical study of the Turbulent Flow Past an Air Foil with Trailing Edge Separation. AIAA Journal, 21(11), 1525-1532. https://doi.org/10.2514/3.8284

Wornom, S., Ouvrard, H., Salvetti, M.V., Koobus, B., Dervieux, A., 2011. Variational Multiscale Large Eddy Simulations of the Flow Past a Circular Cyulinder: Reynolds Number Effects. Computers and Fluids, 47(1), 44-50. https://doi.org/10.1016/ j.compfluid.2011.02.011 